This is the version of the article/chapter accepted for publication in East Asian Pragmatics published by Equinox Accepted version downloaded from SOAS Research Online: http://eprints. soas. ac. uk/id/eprint/30481

\title{
The development of interactional positioning in L2 Japanese
}

\section{Mika Kizu, Barbara Pizziconi and Eiko Gyogi}

\begin{abstract}
The use of the sentence-final particle $n e$ by a group of ten learners of Japanese is investigated longitudinally over a period spanning two years: before, during, immediately after and six-months after return from a year of study in Japan (SA). Quantitative observation reveals two patterns of use; that is, 'prolific' and 'exiguous' styles. Learners in the prolific group display frequent use from before the start of SA, and a subsequent plateau; the others use ne more rarely until after the SA, when the two groups' patterns start converging. In line with previous research, we argue that a certain level of lexical and grammatical competence (which we posit to be at least higher intermediate level) is a precondition for the use of $n e$, but against previous research, we suggest that the amount of naturalistic exposure in an immersion context is not necessarily a decisive factor in its development. Qualitative analysis of the conversational-analytical structuring of interactional meanings (e.g., Ishida, 2009) shows that regardless of the amount of particle use, both groups are able to deploy ne as a marker of interactional alignment in formulaic and non-formulaic tokens. Interestingly, developments can be observed also in the six months after SA, in which all learners increase proportion and/or range of uses of $n e$.
\end{abstract}

\section{Introduction}

Participating in spoken interaction requires the deployment of interactional competence, that is, an ability to develop and manage social interactions in discursively appropriate ways (Hall, 1995). While the term 'communicative competence' conceptualizes a single individual's ability, 'interactional competence' presupposes a sphere of inter-subjectivity: the individual's ability to employ linguistic and interactional resources contingent upon what other participants do and what interactional practices they engage in - including 
rhetorical scripts, vocabulary and syntactic structure, turn management, topic organization, and the opening and closing of boundaries between practices and participation frameworks (He \& Young, 1998; Young, 2011). Compliance with the norms regulating the 'interaction order', including principles of sequence organization, represents a mechanism for managing mutual understanding (Heritage, 2009, p. 306) but also epistemic positioning, which ultimately enables the projection of personal identity (Heritage, 2009, p. 310).

Research is growing on how such a broad range of resources are deployed in the development of interactional competence by second language (L2) learners (Dings, 2016; Nguyen, 2011; Taguchi, 2014; Young \& Miller, 2004). ${ }^{1}$ For example, Taguchi's (2014) study of Japanese L2 learners before and after a period of study abroad (SA) finds that increased use of incomplete sentences contributes to more economical communication (e.g., smoother turn-taking and joint turn construction); increased interactional competence is therefore the result of improved abilities in the co-construction of meanings during talk-in-progress. Similarly, Dings (2016) studies the performance of a Spanish L2 learner during SA and suggests that what enables her to play a more active role in the co-construction of communication is an increased 'alignment activity' (i.e. the use of 'alignment moves' such as collaborative completions, adopting the other's point of view, etc.).

This study attempts to investigate the development of interactional competence in L2 Japanese learners by means of an analysis of their mode of participation in conversation; that is, the way in which learners position themselves vis-à-vis their interlocutors as well as (information exchanged in) the conversation itself. We do this by examining the use of a particular interactional resource, the particle ne ('isn't it?'/'right?') ${ }^{2}$, referred to in the literature as the ultimate 'interactional particle (IP)' (Masuda, 2011, p. 522), by a group of ten learners of Japanese during a relatively long period spanning two years: before, during, immediately after and six-months after return from a SA in Japan. Although studies on interactional markers in L2 Japanese in previous literature abound (Ishida, 2009; Masuda, 2009, 2011; Ohta, 2001; Sawyer, 1992; Yoshimi, 1999), only a few examined them in a longitudinal perspective (e.g., Ishida, 2009; Ohta, 2001; Sawyer, 1992), and as far as we know, mostly in elementary to intermediate learners (with some exceptions, such as Shibahara (2002) and Kizu, Pizziconi \& Iwasaki (2013)). The current study is significant in that (1) it extends the scope of existing investigations (Ishida, 2009; Masuda, 2011; Ohta, 2001; Sawyer, 1992) to a more advanced proficiency group; (2) it explores the possible role of life-style conditions during SA; and (3) it examines the long-term effect of SA, based on the learners' performance 6 months after 
return from SA, when attrition phenomena are often expected. Analysis of the whole corpus is still in progress, but we report some preliminary findings to the following three research questions:

1. Are usage patterns observed in beginner to early intermediate learner populations also observed in our intermediate to advanced learner group?

2. Does the SA context contribute to development in this group, and if so how?

3. Do learners keep developing after return from SA?

Section 2 and 3 respectively review previous studies on ne in native speakers' production and in L2 Japanese. Section 4 outlines our methodology, and results are reported and examined quantitatively and qualitatively in sections 5 and 6. Conclusive observations are sketched out in section 7.

\section{The sentence-final particle 'ne' in native production}

As mentioned in section 1, interactional positioning is discursively achieved by means of strategic usage of a broad range of linguistic resources. Japanese possesses a relatively conspicuous set of linguistic forms indexing discourse participants' stance toward the information and the interlocutor (Ikegami, 1989; Maynard, 1993 among many others), including IPs. Among these, the most frequent is $n e,{ }^{3}$ which we chose for our study of learner behaviour. Studies from diverse disciplinary approaches have highlighted a broad range of meanings and functions of $n e$, as summarized below.

On the more cognitive end, Kamio (1994) discusses ne in terms of 'territory of information' and the speaker's epistemic stance, according to which ne marks information considered to belong to the addressee's territory (in contrast to yo, marking information that belongs to the speaker's own territory), or shared in equal measure by the speaker and his/her interlocutor. In contrast, Takubo \& Kinsui (1997) take ne to signal that the speaker is carrying out cognitive operations independently of their beliefs regarding the hearer's knowledge, and rather in relation to the strength of their own assumptions about the status of the information within a 'mental space' (a 'mental discourse domain', which organizes linguistic expressions and the memory base). Ne assists the organization of such domain, and can signal, for example, that some mental computation is required (that is, information is not easily accessible and needs some degree of processing) in order to make certain statements, even when such information allegedly falls within the speaker's own territory (Takubo \& Kinsui, 1997, p. 755).

Cook (1990), exploring its functions in full turn, turn-internal and turn-final 
positions, finds that the use $n e$ is not limited to "agreement with any particular propositional content" and highlights instead the particle's role in indexing 'affective common ground' (Cook, 1990, p.32) between the speaker and the interlocutor, mitigating face threatening acts and signaling intimacy, or managing discourse structure, such as marking the introduction of a new topic.

Katagiri (2007), noting that sentence-final particles or IPs are typical of spoken and dialogical registers but not written or monological texts, proposes to analyse their functions in terms of what is indeed peculiar to dialogue, that is, the need for ongoing coordination among participants. Dialogue requires the establishment of common ground, and IPs are commonly assumed to consist of acknowledgment responses which facilitate such coordination. In Katagiri's (2007) dialogue coordination account, ne (once again in contrast to yo) is said to present "the propositional content as something the speaker has not yet wholeheartedly accepted" (p. 1317).

However, other research focusing on the dynamics of conversation appears to reach quite different conclusions. Hayano (2017) sees $n e$ as one of the resources the Japanese language possesses to manage epistemics, and notes that it is "used, often reciprocally, when the interactants share access to the referent" (Hayano, 2017, p. 167). Saigo (2011), also examining talk-in-interaction, attempts to capture the role of ne by utilizing the gestalt notion of figure/ground. Content which is accepted by the participants is considered to be a 'ground', upon which new content, yet to be agreed by the participants, is proposed as a 'figure'. $N e$ is said to occur "when the speaker proposes that the figure emerging in the talk should be treated as a ground for the next proposition without further ado. Thus, it typically occurs when he expects that the figure is either already known to the addressee or readily acceptable" (Saigo, 2011, p. 18).

Signaling turn-completion has been considered as one functional motivation for the very development of IPs in Japanese (Fox, Hayashi, \& Jasperson, 1996) but the importance of signaling sequence organization also extends to the projection of expected relevant stances in subsequent turns (Heritage, 2009). From the viewpoint of interactional order, ne could be seen as projecting an alignment (Morita, 2003, quoted in Ishida, 2009) or affiliative action (Tanaka, 2000) in the following turn. These can be seen as the interactional functions of the pragmatic meanings of 'soliciting confirmation' and 'agreement', conventional tags of the particle $n e$ in descriptive analyses and pedagogical definitions. Examining conversation from the viewpoint of speaker 'involvement', Lee (2007) characterizes $n e$ as a particle inviting the "partner's involvement in an 'incorporative' manner, by which the speaker is committed to align with the partner with respect to the contents and feeling conveyed in the utterance" (Lee, 2007, p. 364). 
Conversation analysis thus appears to be a fruitful perspective for the analysis of the role of $n e$ in organizing the contingent and fluid nature of talk-in-interaction (Morita, 2005; Ohta, 2001; Saigo, 2011; Tanaka, 1999, 2000).

In summary, the particle ne occurs not only in sentence- or clausal-final positions, but also in turn-initial and turn-internal positions, and even as a turn on its own; in the flow of interaction, $n e$ is said to yield different effects depending on the sequential context in which it appears, ranging from turn-taking operations to repair initiation, reconfirming an agreed point, or inviting affiliation (Tanaka, 2000; Lee, 2007). Regardless of its position, however, ne utterances are said to signal speakers' alignment to the current activity, or their "mutual orientation for the achievement of situated ongoing conversational intersubjectivity" (a psychological effect of which is the perception of 'common ground' (Morita, 2005, p. 150)). Whichever position it occupies, ne "creates a space for negotiation between interlocutors", therefore earning the label of "interactional particle' (Masuda, 2011, p. 522). The particle ne enables participants to actively engage their interlocutors in the conversation, exerting control on its direction, and indexing an active stance in the exchange, thus positioning the speaker on an even ground with other participants.

\section{Accounts of 'ne' use in non-native production}

While both psychological and conversational interpretations are insightful, controversies over the meanings and functions of ne naturally correspond to difficulties in providing clear-cut explanations to learners of Japanese. In Japanese language instruction, the particle $n e$ is generally introduced in early chapters of beginner-level textbooks (Banno, Ikeda, Ohno, Shinagawa, \& Tokashiki, 2011; Three A Network, 1998). Nevertheless, its acquisition appears to be relatively slow (Ishida, 2009; Masuda, 2009, 2011; Ohta, 2001; Sawyer, 1992; Yoshimi, 1999). Ohta (2001) observed classroom interactions of two beginner-level students over one academic year and found that spontaneous use of ne (i.e. use not prompted by the teacher or instructional materials) appeared only twice by the end of the year. Since the particle is introduced and practiced from early on, this suggests a high level of difficulty. Furthermore, Yoshimi's (1999) qualitative discourse study on five L2 learners of Japanese found a high rate of anomalous uses of ne, which amounted to more than $30 \%$ of their total uses.

A few studies look at the development of ne during SA. Sawyer (1992) observes the use of $n e$ by 11 beginner-level L2 learners of Japanese through four interviews during SA. Despite individual differences, most learners adopt ne rather slowly, some only starting to use it in the third or fourth interview. Ne is generally first used in the formulaic 
expression 'soo desu ne ('Is that so?'/ 'I see'.)' and then deployed in other clauses. Ishida's (2009) conversational analytic study investigates the use of ne by an American student through eight conversations during SA. The learner's proficiency level is not indicated, but Ishida notes that before SA he had studied Japanese for two years in high school and two years at a university; even so, not a single instance of $n e$ was found in the first two conversations. Ishida's study shows how the student came to use $n e$ in a wider range of sequential contexts during $\mathrm{SA}$, and how the expanded use of ne enabled him to take more active roles in his conversations.

Masuda's (2011) study of six learners in an intermediate-level, 6-week summer SA program tests findings in Ohta's (2001) classroom setting and Ohta's hypothesis, regarding the movement from less to more active interactional roles through the development of aligning expressions. According to this, learners must first learn to comprehend and acknowledge the interlocutors' contribution, and then arguably learn to exert more control on the interaction with acts of alignment, that is, agreement and assessment. Ohta's developmental stages are confirmed in the SA context, and situational (reliance on English L1) as well as ideological factors (for example, a male learner's belief that the use of $n e$ is a feature of feminine language) suggested as possible causes of slow development. Masuda concludes that SA constitutes an important opportunity for the development of interactional competence.

To summarize, previous research finds that, with regards to beginner- and intermediate-level L2 learners: i) ne emerges slowly and at the beginning only in formulaic expressions, ii) the range of ne uses increases in the SA context (translating in learners' ability to take more active interactional roles in discourse), but iii) a range of social to psychological factors may constrain its acquisition and use.

Although these studies provide interesting insight into the development of $n e$ and interactional competence of beginner- or post-beginner level learners, the abilities of intermediate- to advanced-level learners are far less studied, and, to our knowledge, development after periods of SA are yet to be investigated. One exception is Matsumura (2007) which, investigating L2 English learners' performance in advice-giving one, six and twelve months after a period of SA, finds that their understanding of relevant strategies keeps developing over this period. The change in the choice of appropriate strategies (in a multiple-choice task) is attributed to the transformation of the learners' perceptions of self over the same period, from 'college students' to 'members of society'.

Our study contributes to the study of a broad learning trajectory, by examining the development of $n e$ in intermediate- to advanced-learners of L2 Japanese over the course of two years, spanning before, during, immediately after, and six months after SA, 
This is the pre-publication version of the paper.

A link to the final published version will be provided in May 2019

including the learners' use of this resource to manage their interactional positioning. 


\section{Methodology}

\subsection{Participants}

The participants were ten intermediate to advanced learners of Japanese (6 males and 4 females), all second-year undergraduates at a university in London, UK at the start of the study. They all majored in Japanese, a four year programme including one year of study at (one of several) Japanese universities. Before going abroad in Year 3, they studied Japanese in an intensive course (eight to ten weekly contact hours) over one or two years ${ }^{4}$. In Year 2, students worked with the textbook New Approach Japanese Pre-Advanced Course (Oyanagi, 2002) and other supplemental material. During SA, students studied Japanese and other relevant subjects at different universities in Tokyo, Osaka, and Kyoto but on a variety of materials and contact hours, which this study could not control. Upon return to the UK, all students except one (Carriad) took an advanced-level Japanese language course for three hours per week. In this class, aiming to reach the $\mathrm{C} 1$ level of CEFR (Common European Framework of Reference for Language), they engaged in critical reading, discussion and academic writing in Japanese.

Table 1 summarizes their profiles (all names are pseudonyms). 
Table 1 Participants' profile

\begin{tabular}{|c|c|c|c|c|c|c|}
\hline Pseudonym & Age & Gender & Nationality & $\begin{array}{l}\text { Previous stay in } \\
\text { Japan }\end{array}$ & $\begin{array}{l}\text { SA } \\
\text { destination }\end{array}$ & $\begin{array}{l}\text { Japanese } \\
\text { course after } \\
\text { SA }\end{array}$ \\
\hline Sakura & 20 & Female & Irish & N/A & Tokyo & Yes \\
\hline Lisa & 20 & Female & British & N/A & Kyoto & Yes \\
\hline Fubuki & 20 & Male & British & Once, 1 week & Tokyo & Yes \\
\hline Rikyuu & 20 & Male & British & N/A & Kyoto & Yes \\
\hline Carriad & 21 & Female & British & $\begin{array}{l}4 \text { times, } 2 \\
\text { months }\end{array}$ & Tokyo & No \\
\hline Solon & 21 & Male & $\begin{array}{l}\text { British/ } \\
\text { American }\end{array}$ & 8 times, 1 year & Tokyo & Yes \\
\hline Bob & 21 & Male & British & Once, 3 weeks & Kyoto & Yes \\
\hline Mimi & 22 & Female & British $^{5}$ & $\begin{array}{l}5 \text { times, } 5 \\
\text { months }\end{array}$ & Tokyo & Yes \\
\hline John & 25 & Male & British & $\begin{array}{l}3 \text { times, } 5.5 \\
\text { months }\end{array}$ & Osaka & Yes \\
\hline Tani & 43 & Male & British & 10 years & Kyoto & Yes \\
\hline
\end{tabular}

All participants have English as mother tongue, and all except one (Tani) are in their 20s. Three out of ten students had never been to Japan before SA, while three (Solon, Mimi and Tani) had already stayed in Japan for one year or more.

\subsection{Research Methods}

The main research instrument are four 15-20 minute interviews conducted over two years. Each interview session was semi-structured, based on three topics (each lasting approximately 5-7 minutes): a) the best place that the interviewee had ever travelled to, b) the most influential person for his/her study, and c) the film, book, or TV program that $\mathrm{s} /$ he watched. The interviews took place before, during, immediately after, and 6 months after SA (hereafter referred to as 'PRE', 'DUR', 'POST-1' and 'POST-2', respectively). The interviewees were only told that data would be used to investigate their development of 
Japanese, and the interviewers did not draw participants' attention to the use of $n e$.

The interviews were carried out by four interviewers, all female native speakers of Japanese teaching the language at different universities, but with different degrees of familiarity with the participants, as described below.

Table 2. Profile of interviewers (at the time of study)

\begin{tabular}{|c|c|c|c|}
\hline Interviewer & Time and place & Affiliation & $\begin{array}{l}\text { Relationship with the } \\
\text { interviewees }\end{array}$ \\
\hline $\mathbf{A}$ & $\begin{array}{l}\text { PRE and POST-2 } \\
\text { (London) }\end{array}$ & $\begin{array}{l}\text { Lecturer at a university in } \\
\text { London }\end{array}$ & $\begin{array}{l}\text { All students knew her, but did } \\
\text { not necessarily take her course } \\
\text { before }\end{array}$ \\
\hline B & $\begin{array}{l}\text { DUR } \\
\text { (Tokyo) }\end{array}$ & $\begin{array}{l}\text { Professor at a university in } \\
\text { Tokyo }\end{array}$ & $\begin{array}{l}\text { Students met her for the first } \\
\text { time }\end{array}$ \\
\hline C & $\begin{array}{l}\text { DUR } \\
\text { (Osaka and Kyoto) }\end{array}$ & $\begin{array}{l}\text { Professor at a university in } \\
\text { Osaka }\end{array}$ & $\begin{array}{l}\text { Students except John met her } \\
\text { for the first time. }\end{array}$ \\
\hline D & $\begin{array}{l}\text { POST-1 } \\
\text { (London) }\end{array}$ & Lector at students' university & $\begin{array}{l}\text { Students' former Japanese } \\
\text { language teacher }\end{array}$ \\
\hline
\end{tabular}

In addition to the interview, a questionnaire including biographical information, the reasons for studying Japanese, learners' expectations regarding SA, and amount of daily use of Japanese outside the classrooms was administered at PRE, DUR, and POST-2. A second questionnaire at DUR further covered their usage of Japanese in and outside the classroom as well as other attitudinal factors, such as their motivation for learning Japanese, integration to Japanese society, and satisfaction with their life. The last questionnaire at POST-2 includes their daily use of Japanese after SA and self-rated achievement of their objectives for SA.

The learner's overall linguistic proficiency was assessed through the Simple Performance-Oriented Test (SPOT) (paper version A) at PRE, POST-1, and POST-2. (cf. Kobayashi, Ford-Niwa, \& Yamamoto, 1996 for an account). SPOT Version A is targeted at higher-level learners of Japanese who studied Japanese for 400 to 800 hours, and consists of filling in a cloze-test while listening to a recording.

\subsection{Analysis}

All interviews were transcribed and coded at a clausal level (all clauses including full 
sentences, subordinate clauses, and intentionally truncated utterances, or fragments). Multi-mora particles including yone and kane, as well as the filler ettone, are not considered in the current study.

All instances of (mono-moraic particle) ne were initially counted to understand overall quantitative changes. Then, the ratio of ne out of all clauses was calculated. The number of soo desu ne ('Is that so?'/ 'I see'.) was separately counted in order to focus on productive or non-formulaic uses, rather than formulaic uses (i.e. soo desu ne). The ratio of ne usage was then measured against SPOT results to explore correlations with proficiency and with some demographic/life-style questionnaire items, to explore possible affecting factors. It was calculated with the use of statistic software R.

In the second part of the study, we focused on two learners who appeared to follow distinct development trajectories. This analysis highlights how each learner positions himself/herself in the course of interaction, and how ne enables such discursive co-construction of their position.

\section{Quantitative Study}

\subsection{Results}

Table 3 below illustrates the frequency of $n e$ in each learner's production at PRE, DUR, POST-1 and POST-2 for each participant. SPOT scores out of 65 are also presented. 
Table 3. Ratio of ne and SPOT test

\begin{tabular}{|c|c|c|c|c|c|c|c|}
\hline & \multicolumn{4}{|c|}{$\begin{array}{l}\text { Ratio of total ne out of all clauses } \\
\text { (raw number of ne (raw number of soo desu ne)) }\end{array}$} & \multicolumn{3}{|c|}{$\begin{array}{l}\text { Japanese proficiency } \\
\text { (SPOT score out of } 65 \text { ) }\end{array}$} \\
\hline & PRE & DUR & POST-1 & POST-2 & PRE & POST-1 & POST-2 \\
\hline Solon & $\begin{array}{r}44.7 \% \\
(55(25))\end{array}$ & $\begin{array}{c}30.0 \% \\
(36(20))\end{array}$ & $\begin{array}{r}21.9 \% \\
(21(16))\end{array}$ & $\begin{array}{c}22.0 \% \\
(29(18))\end{array}$ & 63 & 65 & 65 \\
\hline Fubuki & $\begin{array}{r}26.6 \% \\
(59(46))\end{array}$ & $\begin{array}{r}36.6 \% \\
(60(31))\end{array}$ & $\begin{array}{r}25.5 \% \\
(40(29))\end{array}$ & $\begin{array}{r}23.6 \% \\
(38(33))\end{array}$ & 59 & 64 & 64 \\
\hline Sakura & $\begin{array}{l}16.1 \% \\
(18(8))\end{array}$ & $\begin{array}{c}32.9 \% \\
(50(29))\end{array}$ & $\begin{array}{c}35.3 \% \\
(49(36))\end{array}$ & $\begin{array}{c}31.4 \% \\
(49(37))\end{array}$ & 63 & 65 & 65 \\
\hline Carriad & $\begin{array}{c}19.9 \% \\
(28(23))\end{array}$ & $\begin{array}{r}10.4 \% \\
(21(13))\end{array}$ & $\begin{array}{c}18.6 \% \\
(22(18))\end{array}$ & $\begin{array}{c}11.9 \% \\
(15(11))\end{array}$ & 47 & 56 & 56 \\
\hline Mimi & $\begin{array}{l}10.9 \% \\
(15(11))\end{array}$ & $\begin{array}{l}12.1 \% \\
(27(6))\end{array}$ & $\begin{array}{c}33.6 \% \\
(40(26))\end{array}$ & $\begin{array}{c}15.1 \% \\
(21(14))\end{array}$ & 50 & 62 & 61 \\
\hline Bob & $\begin{array}{l}4.8 \% \\
(5(1)) \\
\end{array}$ & $\begin{array}{c}7.7 \% \\
(13(10))\end{array}$ & $\begin{array}{c}8.5 \% \\
(12(6))\end{array}$ & $\begin{array}{c}14.6 \% \\
(18(12))\end{array}$ & 53 & 61 & 63 \\
\hline Lisa & $\begin{array}{l}4.2 \% \\
(3(3))\end{array}$ & $\begin{array}{l}2.5 \% \\
(3(2))\end{array}$ & $\begin{array}{l}12.5 \% \\
(14(4))\end{array}$ & $\begin{array}{l}13.9 \% \\
(14(2))\end{array}$ & 50 & 61 & 61 \\
\hline Rikyuu & $\begin{array}{l}3.7 \% \\
(3(3))\end{array}$ & $\begin{array}{c}0 \% \\
(0(0))\end{array}$ & $\begin{array}{l}6.2 \% \\
(4(0))\end{array}$ & $\begin{array}{l}8.2 \% \\
(5(0))\end{array}$ & 50 & 60 & 59 \\
\hline John & $\begin{array}{l}2.4 \% \\
(3(1))\end{array}$ & $\begin{array}{l}2.9 \% \\
(2(2))\end{array}$ & $\begin{array}{l}6.3 \% \\
(4(2))\end{array}$ & $\begin{array}{c}17.3 \% \\
(22(15))\end{array}$ & 44 & 60 & 60 \\
\hline Tani & $\begin{array}{l}2.1 \% \\
(2(0))\end{array}$ & $\begin{array}{l}3.1 \% \\
(3(2))\end{array}$ & $\begin{array}{l}4.3 \% \\
(5(5))\end{array}$ & $\begin{array}{l}4.5 \% \\
(4(0))\end{array}$ & 47 & 37 & 48 \\
\hline
\end{tabular}

Our results reveal two patterns of the use, which we call 'prolific' and 'exiguous' styles. Learners in the prolific group (Solon, Fubuki, Sakura, Carriad, Mimi) display frequent use of $n e$ from before the start of SA (10\% or more), and/or a subsequent plateau at some point. In contrast, learners in the exiguous style group (Bob, Lisa, Rikyuu, John, Tani) rarely used $n e$ in both PRE (less than 5\%) and DUR (less than 6\%). Interestingly, the two groups' patterns do not start converging until at POST-2, and remain distinct during and until the end of SA.

Figure 1 below visualises the ratio of $n e$ in Table 1 above by comparing the prolific and exiguous style groups. 


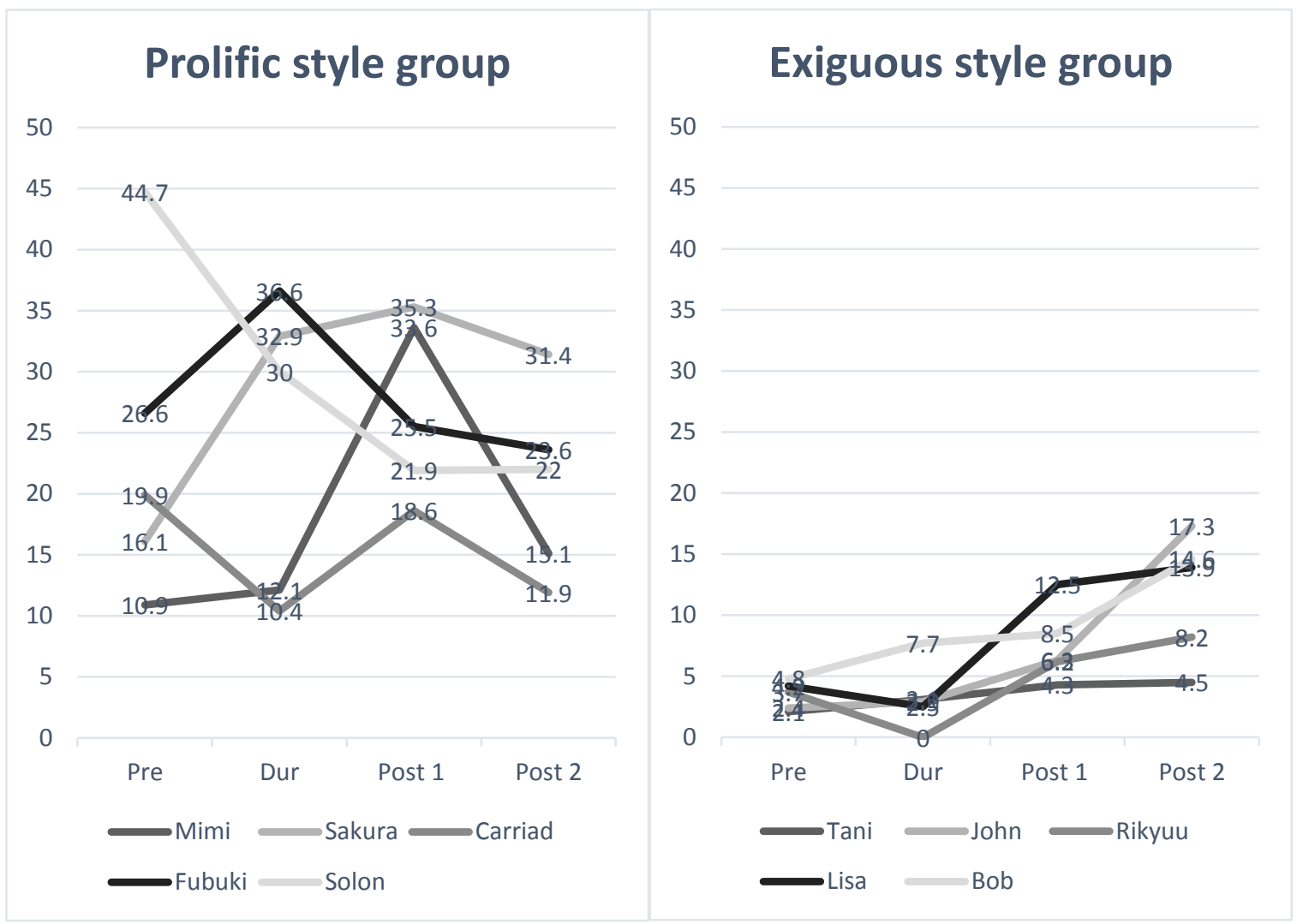

Figure 1. Comparison of the ratio of ne between prolific and exiguous style groups

A distinct patterning is apparent in Figure 1, in that for the duration of the first three stages (PRE, DUR and POST-1), no learner in the exiguous style group used ne as much as learners in the prolific style group. With the exception of two learners (Rikyuu and Tani) who keep using ne very sparingly until the last data point, the others 'catch up' with the more prolific users at POST-2.

All learners improved their score from the first SPOT test at PRE (68\%-97\%) to the last at POST-2 (94\%-100\%, with a possible ceiling effect; See Table 3 above for details). Based on the observations from previous studies, these scores are considered equivalent to Intermediate-High and above, on the ACTFL OPI (Iwasaki, 2002; Masuda, 2009). A strong correlation was observed between the ratio of $n e$ and SPOT results at the start- and end-points of testing, PRE and POST-2 (PRE: $r=0.73, p=* * * 0.002$, POST-1: $r=0.54, p=.1$, POST-2: $r=0.81 * * * p=0.005){ }^{6}$

Although the results of the life-style questionnaires did not flag up any notable differences between the two groups regarding self-reported satisfaction with life in Japan or integration to Japanese society, they show a considerable difference in terms of the self-reported amount of exposure to Japanese during SA. Figure 2 illustrates the average 
hours of Japanese language use for various activities in the prolific and exiguous groups, based on their questionnaire results in DUR.

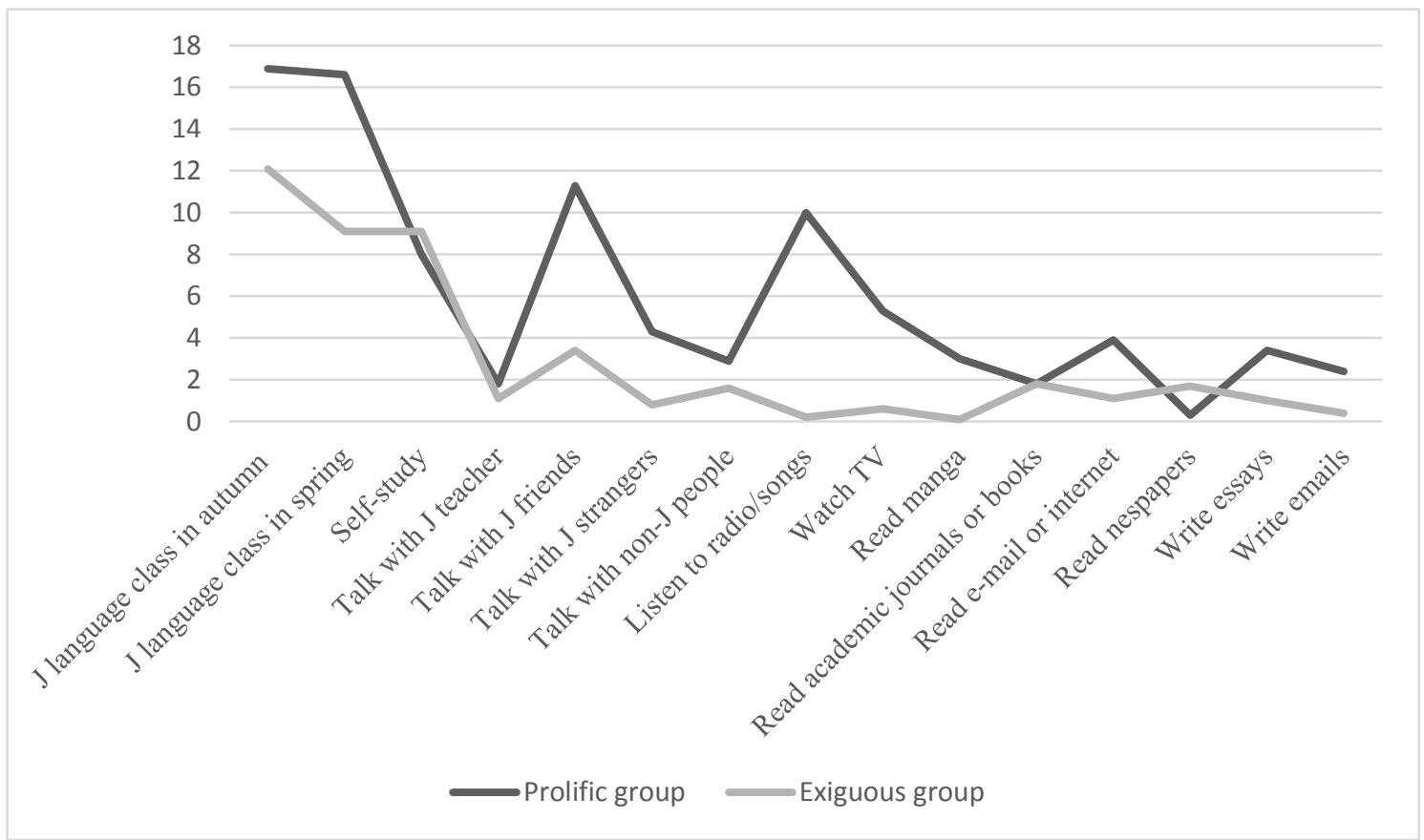

Figure 2. Self-reported average hours of Japanese use during SA ( $\mathrm{J}=\mathrm{Japanese})$

This figure shows that the prolific style group allegedly engaged with Japanese language considerably more than the exiguous style group during SA, exceeding the exiguous group in all items except 'self-study' and 'reading newspapers'. In particular, although both groups engage with teachers to the same extent, the prolific group shows considerably more contact with Japanese friends (11.3 vs 3.4 hours on average).

\subsection{Discussion}

With regards to our first research question, that is, the usage patterns of $n e$, the findings of this study only partially confirm previous studies (cf. Ishida, 2009; Masuda, 2011; Sawyer, 1992) reporting that the use of ne slowly increases following SA. A relatively steady increase was found among learners in the exiguous group, who rarely used ne before SA. In contrast, there was considerable individual variability in the pattern of use of learners in the prolific group, who routinely deploy it already at the start. In an extreme case, Solon's ratio of $n e$ decreased by half after SA, from $44.7 \%$ at PRE to about $22 \%$ at POST-1 and POST-2. Considering the fact that the ratio of ne correlates with learners' SPOT test scores at PRE and POST-2, the prediction of an increase is more likely to hold true for lower proficiency levels than the intermediate and advanced levels we observed. 
Quantitative measures arguably only tell part of the story, distinguishing mostly whether something is yet to appear in a learner's stable repertoire, rather than predicting frequency of use in every encounter, a measure which is naturally subject to the vagaries of the specific interaction.

Regarding research question 2 (i.e. if and how the SA context contributes to development), as our study did not have a control group, our observations remain speculative. However, our analysis of life-style factors did not provide evidence of the effect that could be intuitively anticipated (or desired, from a pedagogical point of view), i.e. more use of $n e$ by those who reported more contact with the Japanese language. The group showing a relatively steady increase in the use of $n e$ during and after SA is the exiguous style group, which according to this self-reported measure engaged quantitatively less with the Japanese language or with a range of Japanese 'others' (teachers, friends, strangers). This suggests, minimally, that amount of contact (even in the immersive context of SA) is not necessarily a decisive factor. The amount of contact is possibly less important than cognitive readiness (i.e. having worked out some meanings of the form) or again subjective and circumstantial factors, such as a more active interactional stance during the interview enabled by, for example, more confidence in one's linguistic skills (or, as in Matsumura, 2007, a different sense of self). Ishida's (2010, pp. 271-272) qualitative study also reports that no obvious difference was observed between learners who went on to SA and those who did not, in terms of evidence of development of interactional competence in conversation data.

In respect to question 3 (i.e. post-SA development), we observed all of the students maintain their use of ne during the interviews six-month after return from SA, but only the exiguous group increasing it, to the point that at POST-2 they 'catch up' (quantity-wise) with the prolific group. This could indicate that the more prolific users had reached an upper limit for a 'natural' use of $n e$ in a context such as this kind of interview (one-to-one, with teacher, etc.) already at previous test points, whereas more room for use was available, in the shape of a more active stance, to the exiguous style users. $^{7}$

Based on the above observations, we would suggest that, after a certain threshold in proficiency has been reached and the learner feels confident enough to positively submit ne-marked comments, the ratio of ne use mostly depends on how each learner wants to interactionally position himself/herself in conversation, based on contextual circumstances as well as the requirements of the particular conversation (including the relationship with the interlocutor, the subject matter, or the tone of the conversation). In order to explore the kind of stance which the use of ne enables our learners to display, we 
note the limitations of a purely quantitative measure of ne production and now turn to a qualitative discussion of our data.

\section{Qualitative Study}

This section focuses on the interactional performance of Lisa in the exiguous style group and Sakura in the prolific group. Because the speaker's stance during a conversation is subject to a myriad of circumstantial factors, we chose interviews with the same interlocutor (interviewer A at PRE and POST-2), so as to keep at least the participants' relation constant, and interviewees of the same gender.

\subsection{Lisa (exiguous style user)}

Lisa, from the exiguous style group, ranks middle in the SPOT scores for this group, and has never been to Japan before SA. Over the course of the four data collection points she moves toward a progressively greater use of ne (cf. Table 3). At PRE, all of the ne occurrences are in the set phrase 'soo desu ne', but from DUR, non-formulaic uses begin to appear. Before we show these, by way of comparison, let us get a sense of Lisa's performance at PRE. We zoom in on her response to the first of the three set questions.

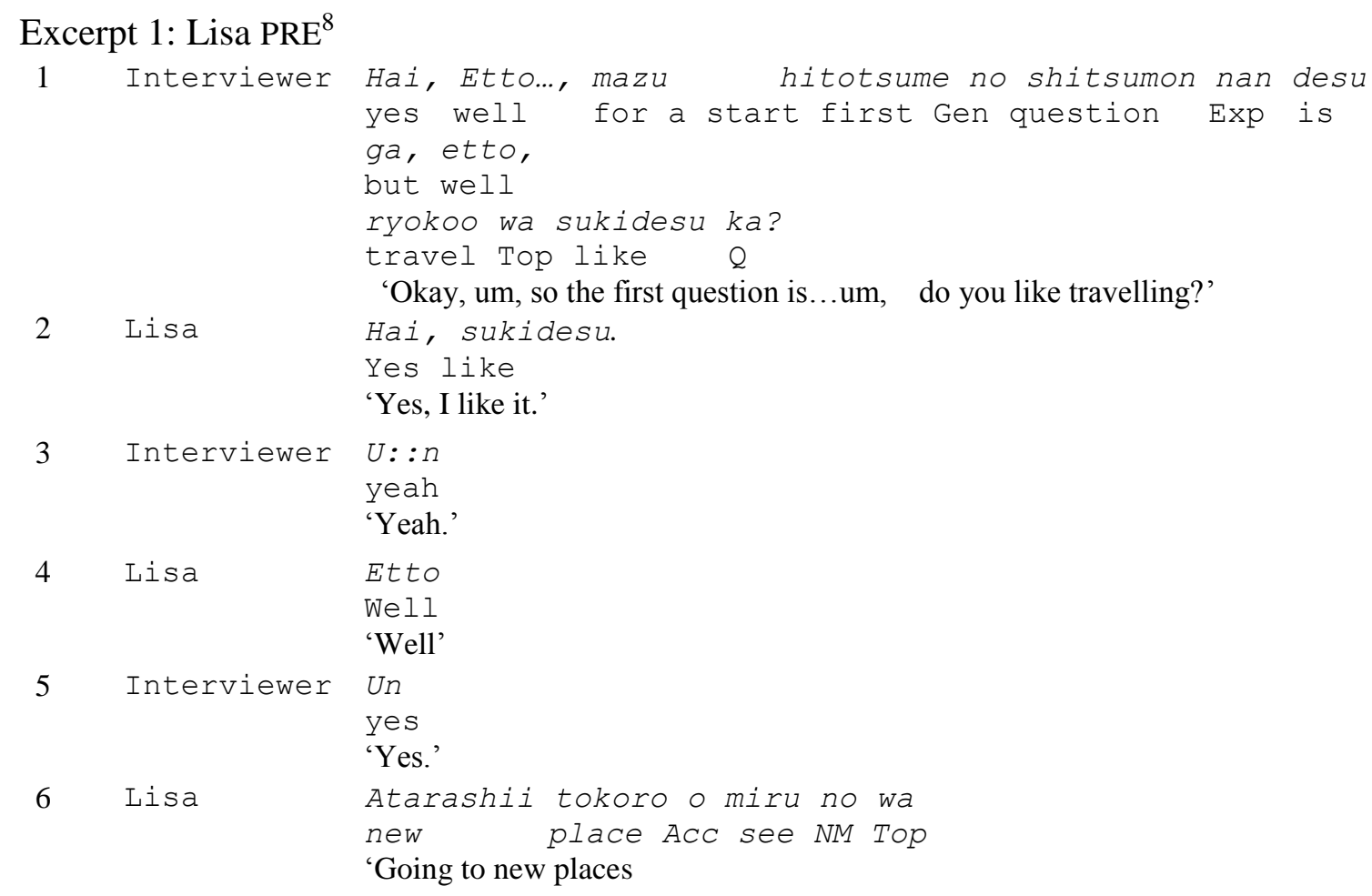




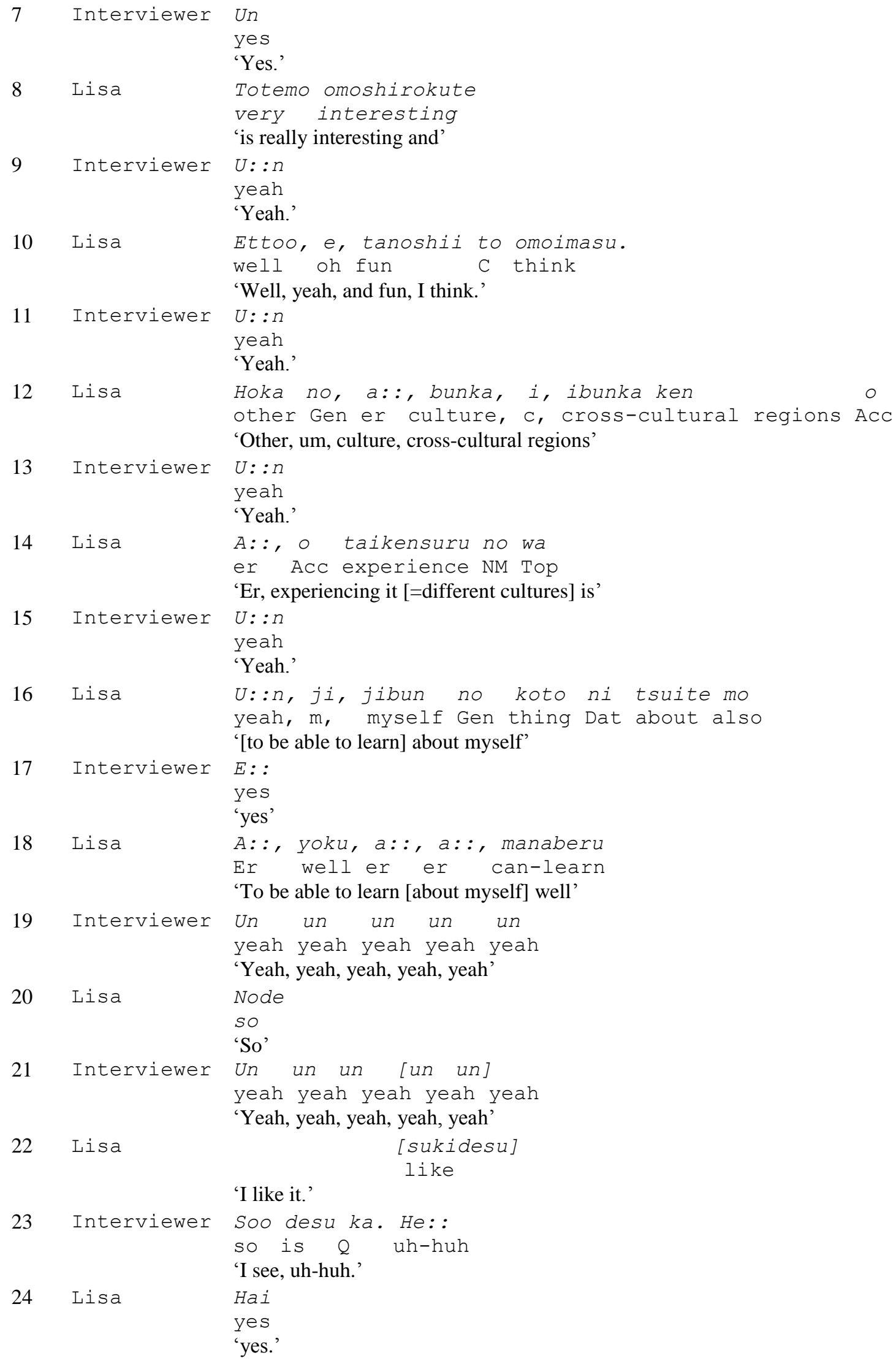


This particular excerpt, recorded at PRE, does not contain any instance of ne. At this point, simply answering the interviewer's questions is enough of a struggle for Lisa, and while she duly answers the interviewer's questions in full and in some detail, her contributions fail to signal a 'dialogic engagement'. As a result, the exchange seems to proceed with a stop-start rather than flowing rhythm. Her answer in line 2 (as the one in line 22) is, for example, an 'unmodalized' statement of her liking travel, more akin to an answer to an interrogation than a turn in a fairly casual conversation. ${ }^{9}$ It is not the case that Lisa struggles with modalization overall; she qualifies her statement in line 10 with to omoimasu '(I) think that'; however, while this utterance thus offers an indication of Lisa's opinion about traveling, it is not offered for further elaboration - a function supported by ne instead. Following Masuda (2011), we could say that Lisa fails to create a 'space for negotiation' for the interlocutors, or with Saigo (2011) that she did not attempt to present the new information as a 'ground' for the interlocutor to further comment on. As Saigo (2011, p. 207) notes, because the particles have no propositional value but only function as metapragmatic and metasequential markers, unexpected usages cause primarily procedural confusion. Indeed, the interviewer's backchannels in lines 3, 11, 23 indicate some temporization, in view of Lisa's minimised participation.

Lisa's performance at POST-2 (six months after SA and two years after PRE) is strikingly different. The passage below in Excerpt 2, just like the one in Excerpt 1, appears in the interviewer's very first question, but on this occasion Lisa's contribution is more fluent, engaged and natural:

\section{Excerpt 2: Lisa POST-2}

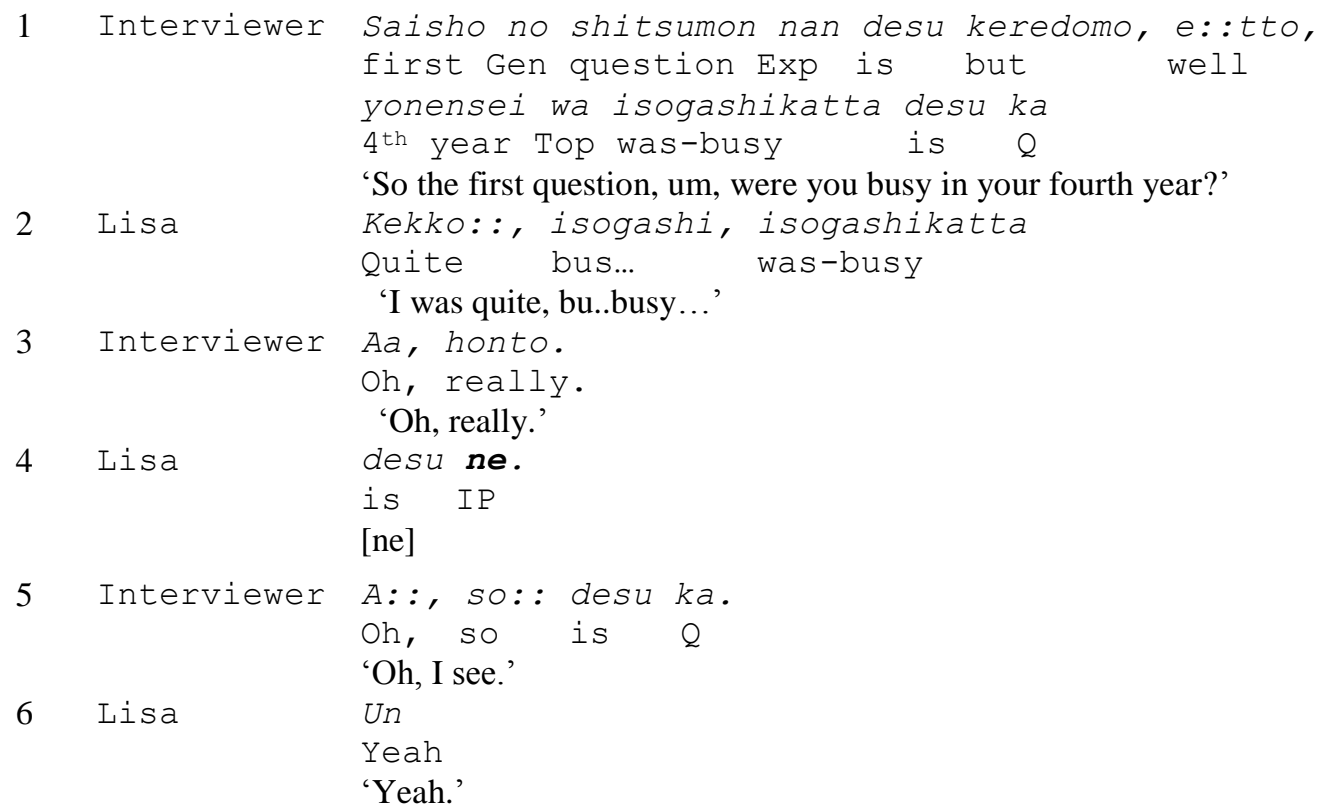


Ja: :, shu: :matsu ni

dokka

dekaketari toka

Then weekends on somewhere go-out or-something Top amari dekinakattadesu ka?

not-much couldn't-do 2

8 Lisa

'Then, you couldn't go out on weekends, could you?'

Ma, toshokan gurai desu ne [a@e]

Well, library only is IP

'Well, (I could go out for) the library only [laugh].'

9 Interviewer [e@e] so: : desu ka.

'[laugh] I see.'

10 Interviewer

Ja, a, Rikyu: :-san mo toshokan [desu ne::] tte

Then, ah, Rikyuu also library is IP C

yutteta node: :

said because

'Then, oh, Rikyuu also said 'it's the library,' so...'

11 Lisa

'Yeah'

12 Interviewer

A, so:: desu ka: :, honto::, u::n

Oh, so is $Q$ really yeah

'Oh, I see. Really. Yeah.'

13 Interviewer

Ma, toshokan mo kireini natte,

Well library also clean became

14 Lisa

'Well, the library was newly built, so'

15 Interviewer

Un

Yeah

'Yeah.'

benkyo:: shiyasuku natta njanai desu ka? study easy-to-do became Exp-not is Q

16 Lisa 'isn't it easier to study there then?'

Un, ma: : kekko:

Yeah, well, pretty much

17 Interviewer

'Well, yes, pretty much so.'

Un

Yeah

'Yeah.'

18 Lisa

Ma, kirei desu shi

Well clean is and

'well, it is clean, and'

19 Interviewer Un

Yeah

'Yeah.'

20 Lisa

nanka, ano::, ma, heya, heya de wa nanka

like umm, well room room in Top like

'Umm, well, ... in my room'

21 Interviewer Un

Yeah

'Yeah.'

22 Lisa

23 Interviewer

Benkyo:: shinikui desu ne, nanka

Study difficult-to-do is IP like

'it's kind of difficult to study...

Un

Yeah

'Yeah.'

24 Lisa

Itsumo nanka, gohan ga tabetai ace

Always like meal Nom want-to-eat 


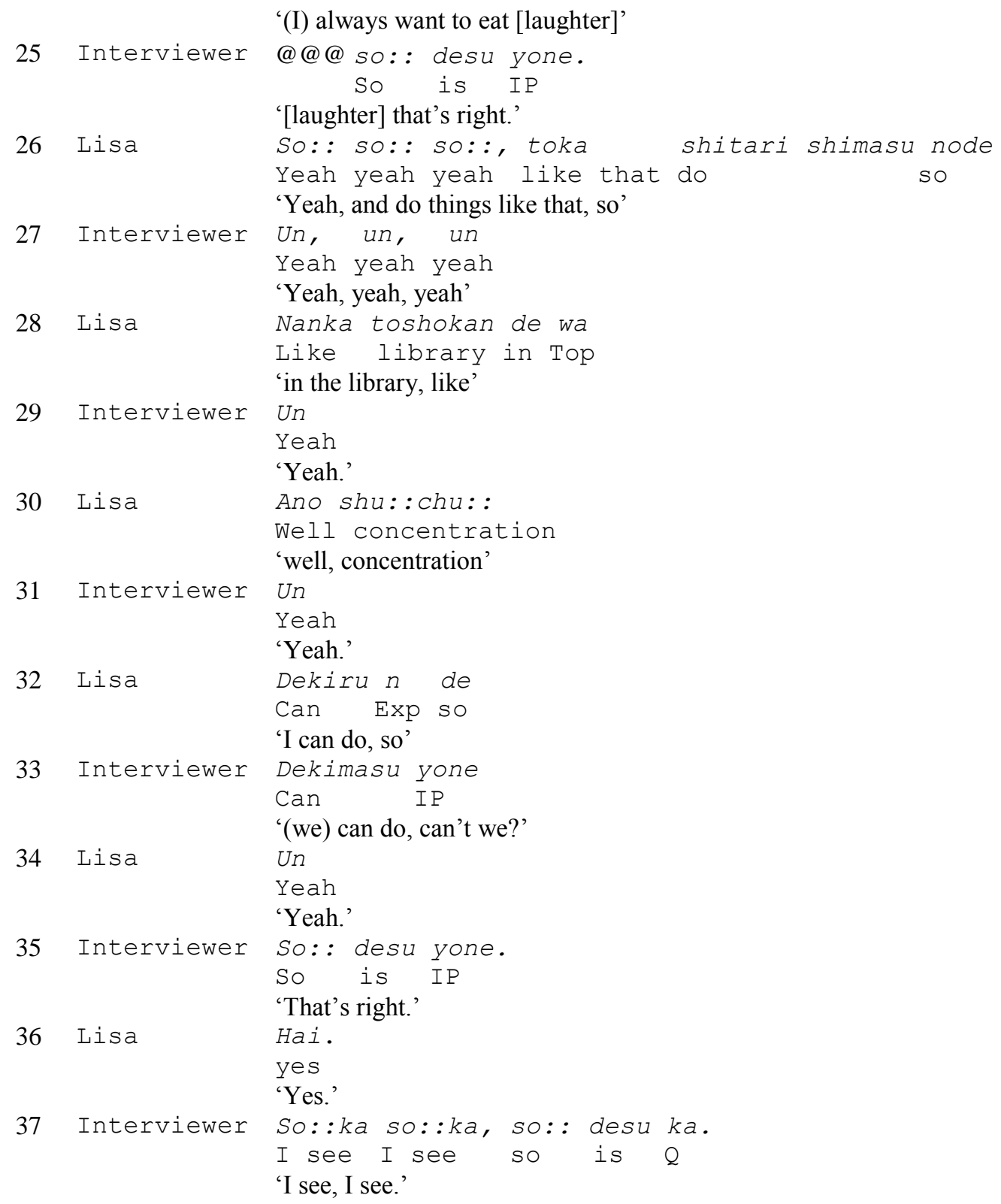

Unlike her response to the first question in Excerpt 1, line 2, Lisa answered the question using ne in line 4 in Excerpt 2: kekkoo isogashikatta desu ne 'I've been relatively busy'. To answer the question literally and merely factually, Lisa does not need to use ne here, but $n e$ effectively invites her interlocutor's reaction, evident in the uptake and the follow up question. By using ne Lisa submits her assessment of a situation, and positively pushes the conversation forward. Similarly, replying to the follow-up question in line 7: 'So, you couldn't go out somewhere over the weekends?', rather than giving a literal and minimal answer: 'No, I couldn't.', Lisa again uses ne to draw the interviewer's attention to the new information she offers '(I went to) just about the library'. Line 22 shows how Lisa qualifies her own opinion in relation to the interviewer's suggestion in line 15. We could 
indeed see these instances as presenting propositional content that Lisa arrived at as a result of some reflection (Takubo \& Kinsui, 1997), but beyond merely manifesting her epistemic stance, through ne Lisa indexes her interactional stance as a co-contributor to the conversation. There are 20 instances like this in total including one instance at DUR, eight at POST-1 and 11 at POST-2 (including those in Excerpt 2 above), showing that Lisa has learned to 'package' information in a way that draws the hearer in, and invites further assessment (a deliberate invitation to 'involvement' in Lee (2007)). The energetic response thus triggered (cf. the acknowledgment of mutual epistemic stance by the interviewer in lines 25, 33 and 35) indeed generates a sense of participants engaged in 'joint intentional activities' (Katagiri, 2007, p. 1316).

\subsection{Sakura (prolific style user)}

Turning now to the prolific group, we examine Sakura as a comparison case. She is a top scorer in the SPOT ranking for the group, but she too had never been to Japan before SA. Her use of ne over the four data sets also increases after moving to Japan (cf. Table 3). The following excerpt comes from the session at PRE and shows part of Sakura's answer to the first question: 'where is the best place you have ever been?':

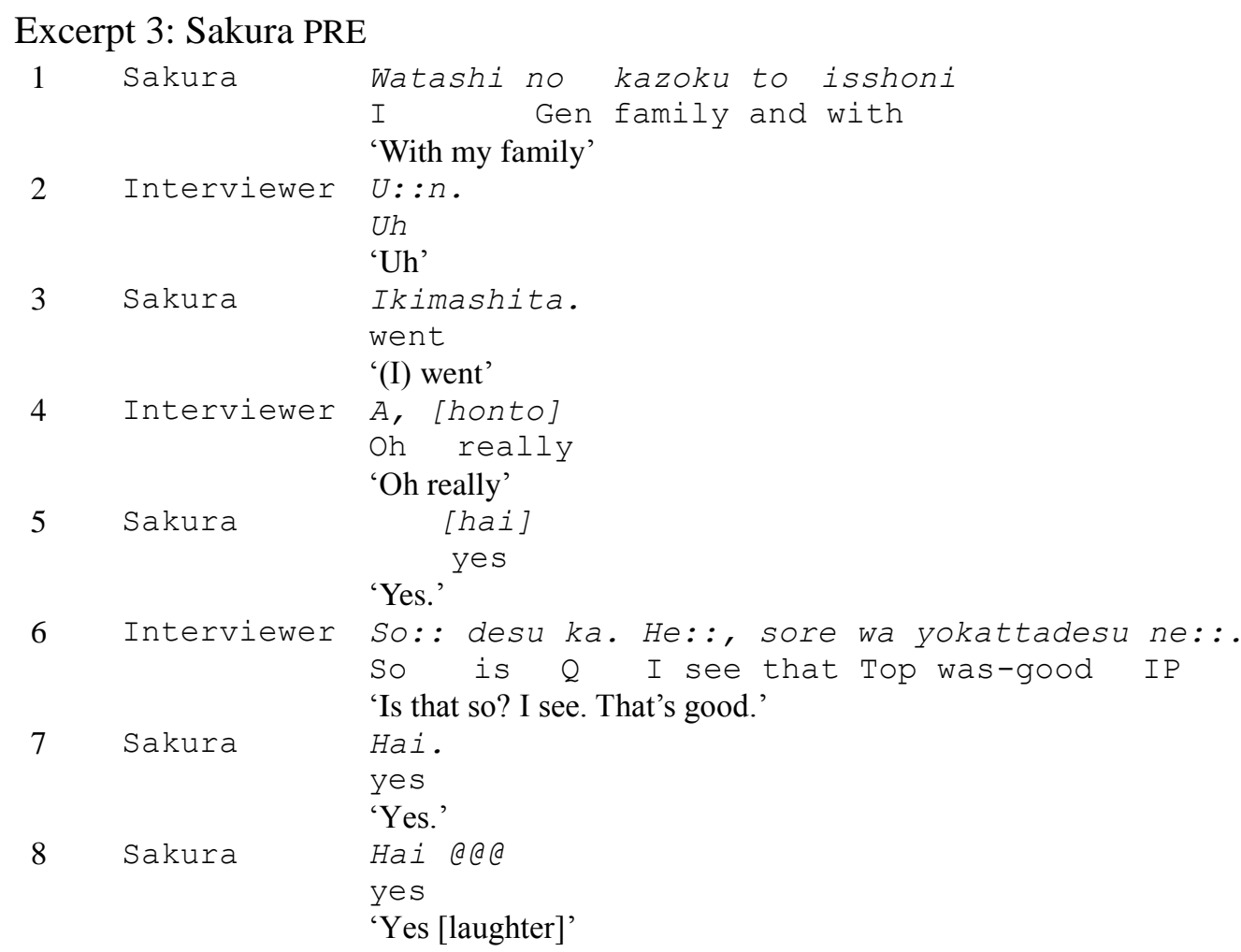




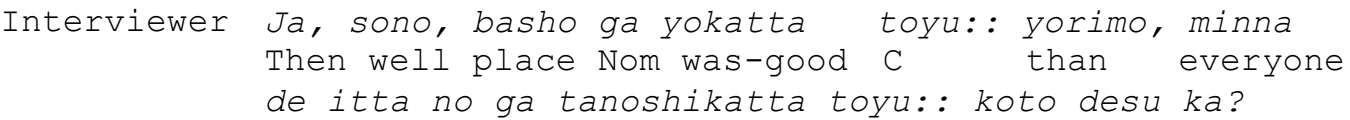

'Then, does that mean that it was fun to go with everyone rather than that you liked the place itself?'

10 Sakura Ma::, ryo: :ho:: desu ne.

Well both is IP

'Well, both, I think.'

11 Interviewer $U:: n$, honto: :

Uh really

'Uh, really.'

Sakura is a frequent user of $n e$ even at PRE, and the instance of $n e$ observed in line 10 above in Excerpt 3 is comparable to the use of ne in line 4, Excerpt 2 produced by Lisa at POST-1 (also in the nuance that the information offered is the result of some 'computation'). This indicates that already at PRE, Sakura knew how to present an assessment as information to be treated as common ground, and inviting the interlocutor's alignment to it, thus taking an active role in the co-construction of discourse.

At POST-2, Sakura's use of ne is increasingly fluent. Excerpt 4 shows the passage in which the interviewer asks her about the most influential person.

\section{Excerpt 4: Sakura POST-2}

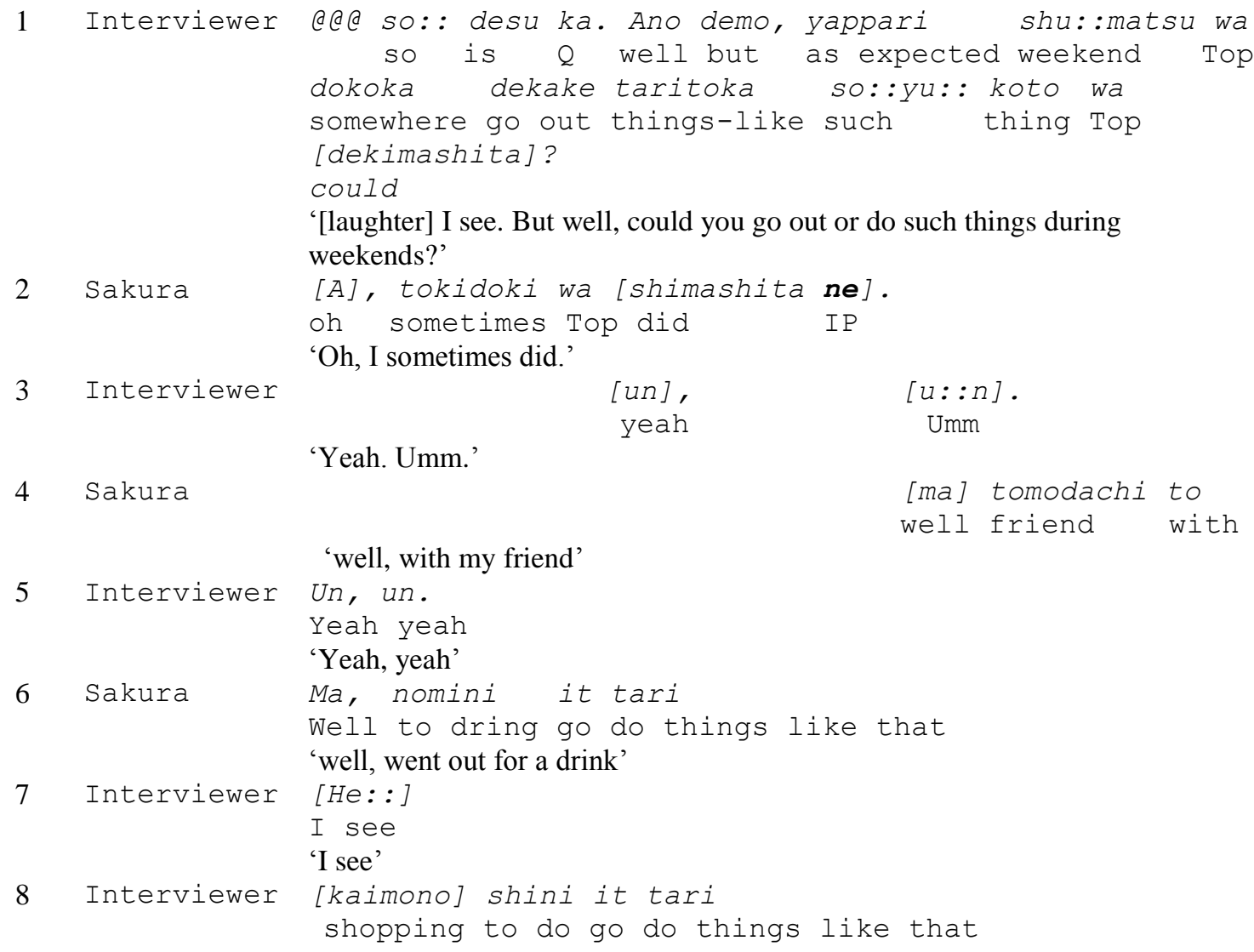


'went out for shopping and something like that'

By using ne in line 2, Sakura answers the interviewer's question promptly and economically. Sakura does not wait for the interviewer to complete the question, as shown in the overlapped utterances in lines 1 and 2, and moreover goes on to provide additional information. Thus ne not only directs the hearer's attention to the proposition preceding it ('yes, sometimes I did go out') but also possibly acts as a pre-sequence: having prepared the ground with her confirmation, with a few subsequent turns from line 4 onward, she enriches her account (duly acknowledged by her interlocutor, including a hee in line 7 flagging up the informativeness of her contribution).

Furthermore, at POST-2 Sakura manages an even more confident interactional positioning. Before the passage quoted here as Excerpt 5, Sakura had said that her boyfriend lived in a place called Itabashi, which prompted the interviewer's comment that her grandmother's house (a stationary shop) was also in Itabashi.

\section{Excerpt 5: Sakura POST-2}

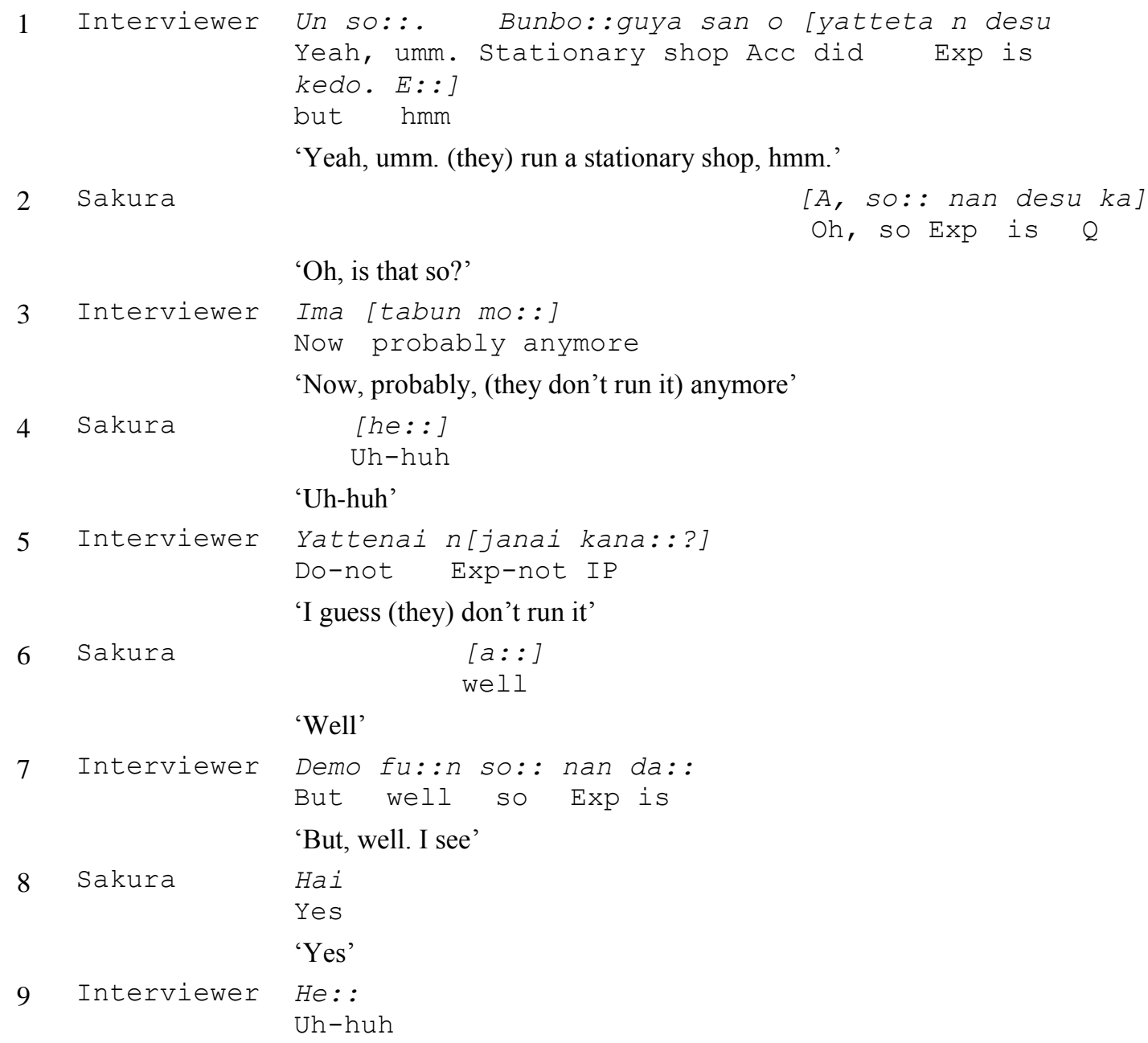




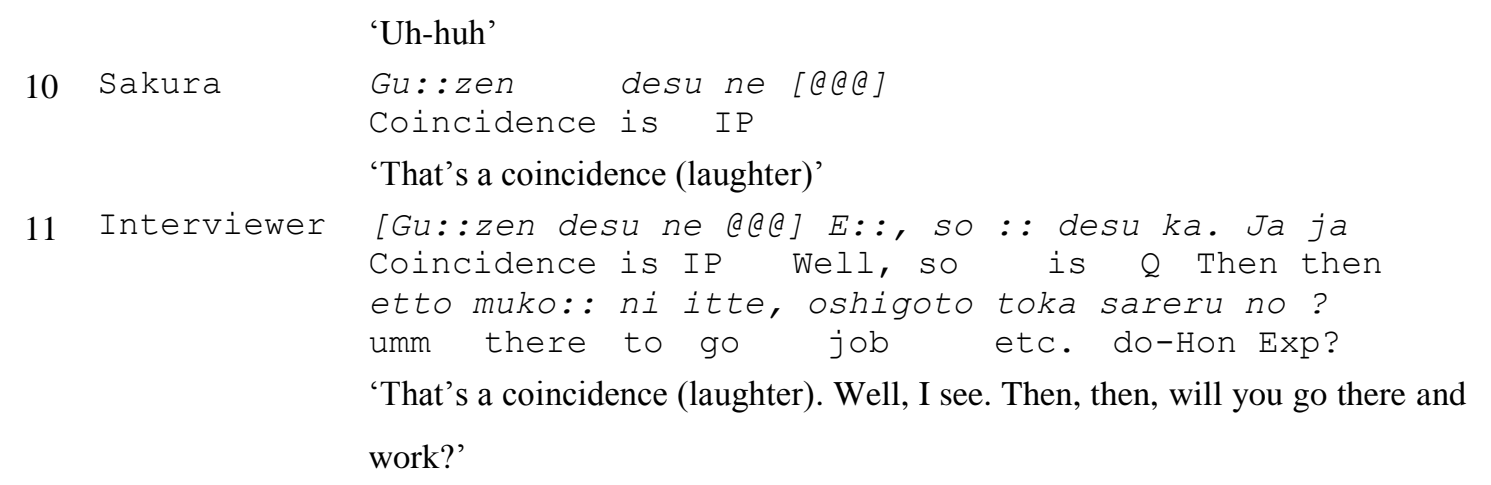

Line 10 is notable in showing Sakura introducing an unsolicited assessment marked by ne, 'guuzen desu ne (That's a coincidence)'. This is very effective in projecting the hearer's alignment in the next turn, evidenced by the interlocutor's repetition of the assessment as well as her mirroring of Sakura's laughter.

Incidentally, a very similar case is observable in Lisa's (exiguous style group) POST-2 dataset. Over the course of about 24 turns, the interviewer had commented on gender inequality in today's Japan in a way which clearly indicated her frustration with the current state of affairs; Lisa had provided appropriate backchannels all along, when she then produced a spontaneous conclusive ne-marked assessment: madamada desu ne ('we are still a long way [from full equality]"!). Lisa can offer this assessment because she has understood her interlocutor's moral or political stance, and is confident not only in stating her own assessment of the situation, but also in inviting, with ne, the interlocutor's alignment in the following turn - which duly arrives, with a repetition of the assessment madamada desu ne. We should note, however, that this is the only unsolicited assessment $n e$ in Lisa's (exiguous group) whole dataset, in contrast with Sakura's (prolific group) who can produce this even from PRE.

\subsection{Final observations on the qualitative analysis}

The analysis of conversation illustrates how the particle ne affords the speaker, among other resources, an instrument for the discursive management of one's interactional position. Our qualitative analysis illustrates how, through ne, learners could emancipate themselves from relatively passive participant positions, mostly responding to the interlocutor's prompts, and achieve more active and even proactive positions, claiming increased agency in the co-construction of the exchange.

The performances of the two learners examined, Lisa and Sakura, who we presented as representatives of the two groups differing in production rates, show how the presence or absence or ne can affect the very nature of the interaction. Through the 
use of an IP which displays the speaker's alignment or invites the interlocutors' alignment, learners were able to create an intersubjective space indexing their interactional orientation beyond the specificities of the propositional content (or rather superimposed on them). By flagging up their interactional stance in the conversation, the learners positioned themselves as legitimate co-participants, and transformed the very exchanges from unilaterally directed interviews to bilaterally managed conversations.

It is not possible to establish unequivocally to what extent confidence in linguistic skills enables a confident interactional stance (the kind of engaged stance marked by $n e$ ), but our qualitative data show the performance of the prolific style learner before the SA to be very similar to that of the exiguous style learner after SA. In other words, prolific users appear to be able to have worked out $n e$ 's potential for interactional positioning (e.g., a mutual alignment) prior to the immersive experience abroad $^{10}$, and to be using it productively whenever circumstantial need arises. The exiguous group would need more time to reach the same level (in terms of amount and range of use), and while this time covers the period spent abroad, it is not clear from our data that the crucial factor for this development is the SA as learning context, rather than just more learning time. Both groups appear to control a diverse range of functions after SA: agreeing with the interlocutors' statements, giving opinions marked by ne in answer to the interlocutor's questions, using $n e$-marked statements to invite and project alignment in the following turns, and producing unsolicited ne-marked assessments. However, we are inclined to conclude that what the learners need to work out is ne's common meaning of 'interactional alignment' and that the above, more specific 'functions' are emergent meanings derived from the interaction of $n e$ with specific contexts of use.

At the current stage of our analysis, still in progress, we are unable to make strong claims with regards to developmental stages, but we wish to submit some brief observations in this respect. Sawyer (1992) among others observes that ne generally appears in the formulaic expression soo desu ne in the early stages, followed by ne in non-formulaic expressions. Stages such as these cannot be detected in our prolific group, since they all used both formulaic and non-formulaic ne throughout the data collection points from PRE to POST-2. Looking at the relevant items in the exiguous group, nonformulaic ne was produced even in the absence of formulaic ne, and even by the least frequent users. As shown in Table 3, for example, Tani at PRE used no formulaic expression but two instances of non-formulaic ne, and Rikyuu at POST-2 produced five non-formulaic ne when he did not use any formulaic one at all. Our prolific users use formulaic slightly more than non-formulaic ne, and more variability in the 'mix' of formulaic/non-formulaic ne is observed as we move toward exiguous style users, but most 
of our learners, with just a handful of exceptions, in fact use both forms in each session in bigger or smaller 'absolute' amounts depending on frequency of use, but in very similar proportions. Thus, as far as our post-beginner level learners are concerned, the developmental pattern observed for the beginners is not applicable; at this stage of development, both formulaic and non-formulaic uses appear to have been appropriated, and are not 'lost' despite infrequent overall use.

\section{Conclusions}

This study explored signs of development of interactional competence, as indexed by the use of the particle ne, in L2 learners of Japanese during and after SA. It is true, as noted by Ishida (2009) and Masuda $(2009,2011)$, that quantitative analyses are blind to local context, without which ne cannot possibly be interpreted. The subjective nature of the interactional stance indexed by ne means that its presence/absence cannot be predicted, especially in spontaneous unscripted conversational contexts, and its measurement is subject to the effects of a myriad of contextual (social, psychological, circumstantial) factors. Our quantitative analysis, however, suggested that proficiency is at least in part a precondition for the use of ne, presumably in terms of a certain level of lexical and grammatical competence as well as efficiency in online processing. But we should qualify this statement by noting that the effect of proficiency is likely more significant at lower levels (as indeed in Masuda's (2011) study). After a certain threshold, which we would roughly place at a higher intermediate level, learners appear to deploy $n e$ in an increasing range of contexts and functions. Because learners are rarely taught this feature in formal instruction (and when they are, it is unlikely to be in terms of the "interactional alignment" function described here) and moreover, because the formal classroom context possibly provides fewer opportunities for use compared to ordinary conversation (Ohta 1994, p. 314-5), it is likely that the learners come to understand its function unconsciously, as a result of exposure to an increasing range of different contexts including extra-curricular activities.

Our study also provides evidence of further development in the period following SA, during which most students (with a few exceptions) either increase or maintain existing levels of $n e$ use. Almost all of those who were using $n e$ only occasionally before or during SA, approximate group-average levels in the 6 months after return, where the two groups behave very similarly.

Our study could not confirm Masuda's (2011) finding that "a study abroad program provides a valuable developmental experience that can accelerate JFL learners' acquisition of interactional competence." Despite its intuitive appeal, because we found 
the group reporting more interaction to be the group changing less, we cannot claim a strong role for the experience abroad. A bias in learners' self-reports could of course be responsible for this unexpected outcome, but another possibility is that because enhanced interactional competence presumably manifests itself first and foremost in terms of a qualitative change in the speaker's stance in the conversation, quantitative correlates are simply not reliable indicators. Further research is necessary to explore this hypothesis.

The participation framework in an activity such as the "research interview" would inevitably prevent learners from considering themselves on an equal footing with the interviewers, and it is not surprising that they showed a more passive role at the outset. However, the qualitative changes we have observed in our learners' behavior over the four sessions lead us to hypothesise that, along with increased linguistic proficiency, the very change in relationship among participants, becoming less formal over time, the increased familiarity with the task, and even a sense of shared knowledge relating to their experience in Japan, allowed a space for the learners to claim a more active role in the interaction. Rather than attempting to demonstrate a causal relationship with specific, single factors, we note that most learners - regardless of what they were able to do at the start of the study - were able to demonstrate a masterful use of $n e$ at the end of the four sessions two years later, to signal (mostly appropriately though sometimes not fully so) such increased agency. The intermediate-high level thus appears to be a crucial phase for gaining and practicing control of the particle $n e$.

The small sample of 10 students is a limitation of the current study with implications for both quantitative and qualitative analyses. Specific idiosyncrasies in any of the interviews may have skewed overall measures and our appreciation of the students' abilities. ${ }^{11}$ Because of the pragmatic nature of $n e$ use, future research can only benefit from the observation of data from spontaneous conversations with different types of interlocutors in a variety of social settings, and not limited to semi-structured oral interviews.

The observations on more advanced proficiency learners in this study qualify earlier generalisations about learning trajectories, and problematise the role of SA experience in the development of $n e$ as an index of interactional competence. Further exploration of correlations between $n e$ and other modal markers would arguably enhance such observations, but we will leave this for our future research.

\section{Acknowledgements}

We wish to express our gratitude to the editors and anonymous reviewers for their exceptionally prompt, thorough and very constructive comments on our draft. Naoko 
Taguchi offered valuable comments on a preliminary version of this paper, for which we thank her sincerely. Remaining inaccuracies are ours alone. We would also like to thank all the participants, students and teachers alike, who collaborated to this project. The study was supported by JSPS KAKENHI [grant number 17K02999].

\section{References}

Banno, E., Ikeda, Y., Ohno, Y., Shinagawa, C., \& Tokashiki, K. (2011). Genki I: An Integrated Course in Elementary Japanese (2nd ed.). Tokyo: The Japan Times.

Cook, H. M. (1990). The sentence-final particle ne as a tool for cooperation in Japanese conversation. In H. Hoji (Ed.), Japanese/Korean linguistics (Vol. 1, pp. 29-44). Stanford, CA: Center for the Study of Language and Information.

Dings, A. (2016). Interactional competence and the development of alignment activity. The Modern Language Journal, 98(3), 742-756.

Fox, B. A., Hayashi, M., \& Jasperson, R. (1996). Resources and repair: A crosslinguistic study of syntax and repair. In E. Ochs, E. A. Schegloff, \& S. A. Thompson (Eds.), Interaction and grammar (pp. 185-237). Cambridge: Cambridge University Press.

Hayano, K. (2017). When (not) to claim epistemic independence: The use of $n e$ and yone in Japanese conversation. East Asian Pragmatics, 22(2), 163-193.

Hall, J. K. (1995). “Aw, man, where you goin'?’': Classroom interaction and the development of L2 interactional competence. Issues in Applied Linguistics, 6(2), $37-62$.

He, A. W., \& Young, R. (1998). Language proficiency interviews: A discourse approach. In A. W. He \& R. Young (Eds.), Talking and testing: Discourse approaches to the assessment of oral proficiency (pp. 1-24). Amsterdam: John Benjamins.

Heritage, J. (2009). Conversation analysis as social theory. In B. S. Turner (Ed.), Blackwell handbook of social theory (pp. 300-320). Oxford: Blackwell.

Ikegami, Y. (1989). Nihongo no tekusuto to komyunikeeshon. [Texts and communications in Japanese]. In K. Inoue (Ed.), Nihon bunpoo shoojiten. [Concise dictionary of Japanese grammar] (pp. 245-266). Tokyo: Taishukan Shoten.

Ishida, M. (2009). Development of interactional competence: Changes in the use of ne in L2 Japanese during study abroad. In H. thi Nguyen \& G. Kasper (Eds.), Talk-inInteraction: Multilingual perspectives (pp. 351-385). Honolulu, HI: University of Hawai'i, National Foreign Langauge Resource Center.

Ishida, M. (2010). Development of interactional competence in L2 Japanese during 
study abroad: The use of modal expressions in recipient actions. Unpublished $\mathrm{PhD}$ dissertation, University of Hawai'i.

Iwasaki, N. (2002). Nihongo nooryoku kani shiken (SPOT) no tokuten to ACTFL kootoo nooryoku (OPI) no reberu no kankei ni tsuite [Simple performance-oriented test (SPOT) vs. oral proficiency interview (OPI)]. Journal of Japanese Language Teaching, 114, 100-105.

Kamio, A. (1994). The thoeroy of territory of information: The case of Japanese. Journal of Pragmatics, 21(1), 67-100.

Katagiri, Y. (2007). Dialogue functions of Japanese sentence-final particles "yo" and “ne.” Journal of Pragmatics, 39(7), 1313-1323.

Kizu, M., Pizziconi, B., \& Iwasaki, N. (2013). Modal markers in Japanese: A study of learners' use before and after study abroad. Japanese Language and Literature, 47, 93-133.

Kobayashi, N., Ford-Niwa, J., \& Yamamoto, H. (1996). Nihongo nouryoku no atarashii sokutei-hoo: SPOT. [A new way of measuring integrative ability of Japanese: SPOT]. Japanese Language Education in Education around the Globe, 6, 201217.

Lee, D. (2007) Involvement and the Japanese interactive particles ne and yo. Journal of Pragmatics, 39 (2), 363-388.

Masuda, K. (2009). Learners' use of Japanese interactional particles in student-teacher conversations. Japanese Language and Literature, 43, 335-362.

Masuda, K. (2011). Acquiring interactional competence in a study abroad context: Japanese language learners' use of the interactional particle ne. The Modern Language Journal, 95(4), 519-540.

Matsumura, S. (2007). Exploring the aftereffects of study abroad on interlanguage pragmatic development. Intercultural Pragmatics, 4-2, 167-192.

Maynard, S. K. (1993). Discourse modality: Subjectivity, emotion, and voice in the Japanese language. Amsterdam: John Benjamins.

Morita, E. (2003). The Japanese interactional particles ne and sa: An analysis of their conditional relevance for conversation. Unpublished $\mathrm{PhD}$ dissertation, University of California.

Morita, E. (2005). Negotiation of contingent talk. Amsterdam: John Benjamins.

Nguyen, H. thi. (2011). A longitudinal microanalysis of a second language learner's participation. In G. Pallotti \& J. Wagner (Eds.), L2 learning as social practice: Conversation-analytic perspectives (pp. 17-44). Honolulu, HI: University of Hawai'i, National Foreign Language Resource Center. 
Ohta, A. S. (1994). Socializing the expression of affect: An overview of affective particle use in the japanese as a foreign language classroom. Issues in Applied Linguistics, 5(2), 303-325.

Ohta, A. S. (2001). A longitudinal study of the development of expression of alignment in Japanese as a foreign language. In K. R. Rose \& G. Kasper (Eds.), Pragmatics in language teaching (pp. 103-124). Cambridge: Cambridge University Press.

Oyanagi, N. (2002). Nyuu apuroochi chuujookyuu nihongo kansei hen[New Approach Japanese: Pre-Advanced Course]. Tokyo: Gobun Kenkyūsha.

Saigo, H. (2011). The Japanese sentence-final particles in talk-in-interaction. Amsterdam: John Benjamins.

Sawyer, M. (1992). The development of pragmatics in Japanese as a second language: The sentence-final particle ne. In G. Kasper (Ed.), Pragmatics of Japanese as a native and target language (pp. 83-125). Honolulu, HI: University of Hawai'i.

Shibahara, T. (2002). Ne no shuutoku: 2000/2001 chooki kenshuu OPI deeta no bunseki [Acquisition of $n e ;:$ Analysis of the OPI data during the 2000-2001 long-term training]. Nihongo Kokusai Sentaa Kiyoo, 12, 19-34.

Taguchi, N. (2014). Development of interactional competence in Japanese as a second language: Use of incomplete sentences as interactional resources. The Modern Language Journal, 98(2), 518-535.

Takubo, Y., \& Kinsui, S. (1997). Discourse management in terms of mental spaces. Journal of Pragmatics, 28, 741-758.

Tanaka, H. (1999). Turn-taking in Japanese conversation: A study in grammar and interaction. Amsterdam: John Benjamins.

Tanaka, H. (2000). The particle ne as a turn-management device in Japanese conversation. Journal of Pragmatics, 32, 1135-1176.

Three A Network. (1998). Minna no nihongo shokyuu I honsatsu [Japanese for Everyone beginners I main book]. Tokyo: Three A Network.

Yoshimi, D. R. (1999). L1 language socialization as a variable in the use of ne by L2 learners of Japanese. Journal of Pragmatics, 31, 1513-1525.

Young, R. F. (2011). Interactional competence in language learning, teaching, and testing. In E. Hinkel (Ed.), Handbook of research in second language teaching and learning Volume 2 (pp. 426-443). New York: Routledge.

Young, R. F., \& Miller, E. R. (2004). Learning as changing participation: Discourse roles in ESL writing conferences. The Modern Language Journal, 88(4), 519-535. 
${ }^{1}$ While we are aware that a distinction has been made in previous literature between 'second' and 'foreign' language learners, this paper calls them second language (L2) learners for convenience sake.

2 As can be appreciated through the literature review section, a straightforward translation of the modal particle ne into English is not possible. The particle has no referential meaning, and the English gloss we offer above is but an approximation of one of its many indexical functions.

3 Masuda's (2009, p. 343) study of IPs in one-to-one conversations between six Japanese college students and their teachers reports $n e$ to be the most frequently used $(45.7 \%$, compared to yo $29.3 \%$; yone $17.3 \%$, kana $5.2 \%$ and kane/kana $2.5 \%$ ).

${ }^{4}$ This variation is due to the fact that three out of ten participants (Solon, Fubuki and Sakura) had prior knowledge of Japanese and entered the programme from the second year, while the other seven participants started from the first year. The syllabus covered at the end of the second year and prior to SA was therefore nominally the same for all participants, although variation in command of such content could be expected.

${ }^{5}$ Mimi is half Japanese and visited her relatives in Japan frequently before SA. However, she declared that she did not use Japanese at home and her first language was English.

6 Although POST-1 SPOT results do not significantly correlate with ne, they do correlate if we only focus on sentence-final ne after excluding the formulaic soo desu ne (PRE: $r=$ $0.75, * p=.01$, POST $-1: r=0.69 * p=.03$, POST $-2: r=0.60 * p=.07)$. The weaker correlation with POST-2 is likely due to the convergence of proficiency between the two groups and the possible ceiling effect.

${ }^{7}$ The case of Tani in the exiguous group is emblematic: his SPOT test score increases only slightly but remains low even after SA (72\% at PRE; 74\% at POST-2) compared to other learners in the exiguous style group (whose score increases from $68 \%-82 \%$ at PRE to more than $90 \%$ at POST-2). Tani's ratio of $n e$ also remained the lowest (4.5\% at POST2) while other students in the exiguous group approximate the pattern of the prolific group $(8.2 \%-17.3 \%)$ at POST-2. This suggests that a certain proficiency level is a threshold that must be reached before $n e$ becomes available.

${ }^{8}$ The transcription conventions and abbreviations used in this paper are as follows:

- = falling intonation, $?=$ rising intonation, $::=$ lengthened segment, []$=$ overlapping, $\triangle \Theta \subseteq=$ laughter, $\mathrm{ACC}=$ accusative marker, $\mathrm{C}=$ quotation marker, $\mathrm{Dat}=$ dative marker, $\mathrm{Exp}=$ explanatory marker, Gen = genitive marker, Hon = honorific, $\mathrm{NM}$ $=$ nominalizer, $\mathrm{Nom}=$ nominative marker, $\mathrm{Q}=$ question marker, $\mathrm{IP}=$ interactional particle, $\mathrm{Top}=$ topic marker

${ }^{9}$ Of course Lisa's framing of the interview may be rather different: rather than a casual conversation she may have felt as though she was being tested. However, her contribution is appropriate to the question only content-wise: she is describing what she likes about traveling and submitting more information than yes/no answers; however, this propositional appropriateness is arguably not matched by procedural appropriateness.

${ }^{10}$ This is in spite of the shorter amount of instruction our learners received: Lisa in the exiguous group had 2 years of tuition before SA, and Sakura just one (as noted in section 4.1 and footnote 4 ).

11 For example, our most prolific user, Solon, shows a record production in the first 
session but then a steady decrease over time $(44 \%, 30 \%, 22 \%, 22 \%)$. There is no 'loss' of ability of course, but just a different 'tone' over the sessions, each of which, as we noted elsewhere, is a unique event. 